\title{
Assessment methodology of concrete crack resistance on cement binder
}

\author{
Valeriy Popov ${ }^{1}$, Dmitry Popov ${ }^{1}$, and Anna Davidenko, ${ }^{1, *}$ \\ ${ }^{1}$ Samara State Technical University, Academy of Architecture and Civil Engineering, 443001, \\ Samara, Molodogvardeyskaya Str., 194, Russia
}

\begin{abstract}
The study examines a methodology based on the assessment of factors which further influence properties of concrete, that is its physical and mechanical characteristics analysis. The methodology is based on the research results obtained in the Samara School of Material Engineering and previously developed by the authors themselves. Its essence is based on the study of concrete destruction processes with account of existing rules of fracture mechanics. The researchers merged the energy conception of A.A. Griffiths with the kinetic theory of S.N. Zhurkova and developed a mathematical apparatus capable of modeling the conditions of external influence on concrete. They also estimated "Rebindera effect" while applying external load from the described types of external influence. They determined three stages in the course of destruction development depending on quantity and quality of initial defects. The first stage of destruction occurs at the micro level, the destruction is negligible. At the second stage cracks begin to fuse and already influence on change of values of concrete stress-strain properties. Finally, the third stage is "direct fracture" when the main cracks are formed dividing the specimen into separate fragments not capable of carrying the external load. The work reveals parameters and divide them into two groups. These parameters have a significant influence on the nature and kinetics of the destruction processes, respectively. The authors introduce a criterion of concrete crack resistance named "the length of the reduced crack". This criterion represents the total length of all surfaces of destruction at a single width of a crack. The proposed method can be applied with the use of nondestructive acoustic methods and destructive mechanical methods. Approbation of this methodology showed sufficient reliability and authenticity of the proposed indicator as a criterion of crack resistance.
\end{abstract}

\section{Introduction}

The researchers of various departments of the Academy of Construction and Architecture of Samara state technical university are engaged in the development of methods for evaluating the physico-mechanical characteristics of various materials [1-5] and the optimal design of structures from various materials [6-28].

\footnotetext{
*Corresponding author: aezg@mail.ru
} 
Numerous studies carried out in the field of destruction of brittle materials, including concrete, have shown that the latter are destroyed due to the development of cracking processes. The complexity of the structure of concrete is in the multicomponent mixture of polycrystals interacting with one another according to physical and chemical laws and the impossibility of predicting it at the stage of making a sample or design, respectively. In concrete with any structure, there are defects in the form of microcracks and pores that appeared in it in the process of formation. These defects cause the development of cracks and adsorption of a sufficient amount of moisture on their surface.

External impact of any kind (power, hydrostatic, temperature, humidity) cause the cracks in the concrete. Moreover, the process of their development goes in the energyfavorable direction for them, namely, in zones subject to the effect of "prestressing". In the future, the load applied to the material will decrease by the amount of "prestressing". This effect was called the "Rebinder effect". With a further increase in the load, flat cracks of various sizes are formed due to the intergrowth of microcracks in macrocracks. The latter lead to the destruction of the material, the loss of its operational properties and the inability to perceive external impact.

\section{Materials and methods}

The process of destruction of concrete, from the energy point of view, has three stages [2931]. All three stages, which differ significantly from each other by the energy released during cracking. At the first stage, cracks develop at the micro level, from micropores or microdefects existing in the concrete structure. The dimensions of the microcracks formed are insignificant, and the energy of crack formation is small. These cracks practically do not affect the values of the physical and mechanical characteristics of the material and when the load increase stops, it will not affect the operation of the structure. At the second stage, called the stage of preparation of fracture and the amount of external action that comes with increasing, the microcracks reach such dimensions that their influence can be evaluated by changing the values of the physical and mechanical characteristics of the concrete. At this stage we observe the process of the transition of microcracks into macrocracks. At the same time, the energy of crack formation is higher than at the first stage. Finally, we observe the formation of main cracks, which at the last stage split the concrete into parts. The energy of crack formation at this stage is twice greater than at the second stage. Destruction is fragile.

The kinetics and nature of the destruction of concrete largely depend on the amount and type of initial defects of concrete. The larger the defects existing in the concrete structure are, the faster the concrete breaks down and the less external impact is required to destroy it. To assess this phenomenon in concrete practice, a value called crack resistance of concrete is adopted. Many methods have been developed for its determination. Most of the techniques either do not have quantitative indicators, or these indicators are determined at the level of measurement error. The reliability of such indicators is doubtful.

Thus, for example, the existing assessment of the fracture toughness of concrete by its porosity, by which is meant the integral volume of all defects in the structure of concrete, has a significant disadvantage in that modern con-cretes have a porosity in the range of no more than $0.5 \ldots 1.5 \%$, and their physico-mechanical characteristics may differ by several times. In this situation, there was an urgent need to develop a method for estimating crack formation, which, firstly, would have quantitative parameters above the measurement error, and secondly, would be based on theoretical studies related to the processes of material destruction. The method of estimating the cracking of concrete presented below, in the opinion of the authors of this work, meets this need. 
Modern processes describing the actual operation of any kind of structures and the behavior of structural materials cannot be imagined without the achievements of fracture mechanics. The researchers A.A. Griffiths and S.N. Zhurkov [32, 33] founded the most reliable way to describe the destruction of concrete on the basis of the energy theory and the kinetic concept of fracture mechanics.

\section{Results}

Studies of the destruction processes of concrete carried out by the authors for a number of years [29-31] have shown that the nature and kinetics of concrete destruction processes are affected by two types of characteristics: the initial parameters of the concrete structure and the kinetic characteristics of the processes of its destruction. The first group includes such physical and mechanical characteristics of the structure of concrete as surface energy, modulus of elasticity, Poisson's ratio, compressive strength. The second group includes the propensity of concrete to crack formation and the intensity of cracking. Kinetic characteristics are used to classify the intensity of external influences on the material. These same studies have shown that a definite and theoretically grounded ratio of the initial physicomechanical characteristics can be used as a criterion for the fracture toughness of concrete. In the physical sense, the proposed criterion is a characteristic of the fracture surface destruction.

The length of the reduced crack $\left(L_{r c}\right)$ is quantitatively represented in meters, representing the total length of all the main cracks formed in the sample when directly destroyed, having a reduced width of $1.00 \mathrm{~m}$.

The combination of these parameter is represented in the equation:

$$
L_{r c}=\frac{2 E v}{\pi \mu^{2} R_{s}^{2}}
$$

in which: $L_{r c}$ - The length of the reduced crack, m;

$E$ - elasticity modulus, $\mathrm{MPa}$;

$\mu$ - Poisson's ratio;

$v$ - surface energy, J;

$R_{s^{-}}$compressive strength, $\mathrm{MPa}$.

The methodology for determining the crack resistance of concrete, protected by patents $[34,35]$, was developed, based on the carried out studies. The experiment was carried out on samples under air-dry and water-saturated conditions. 


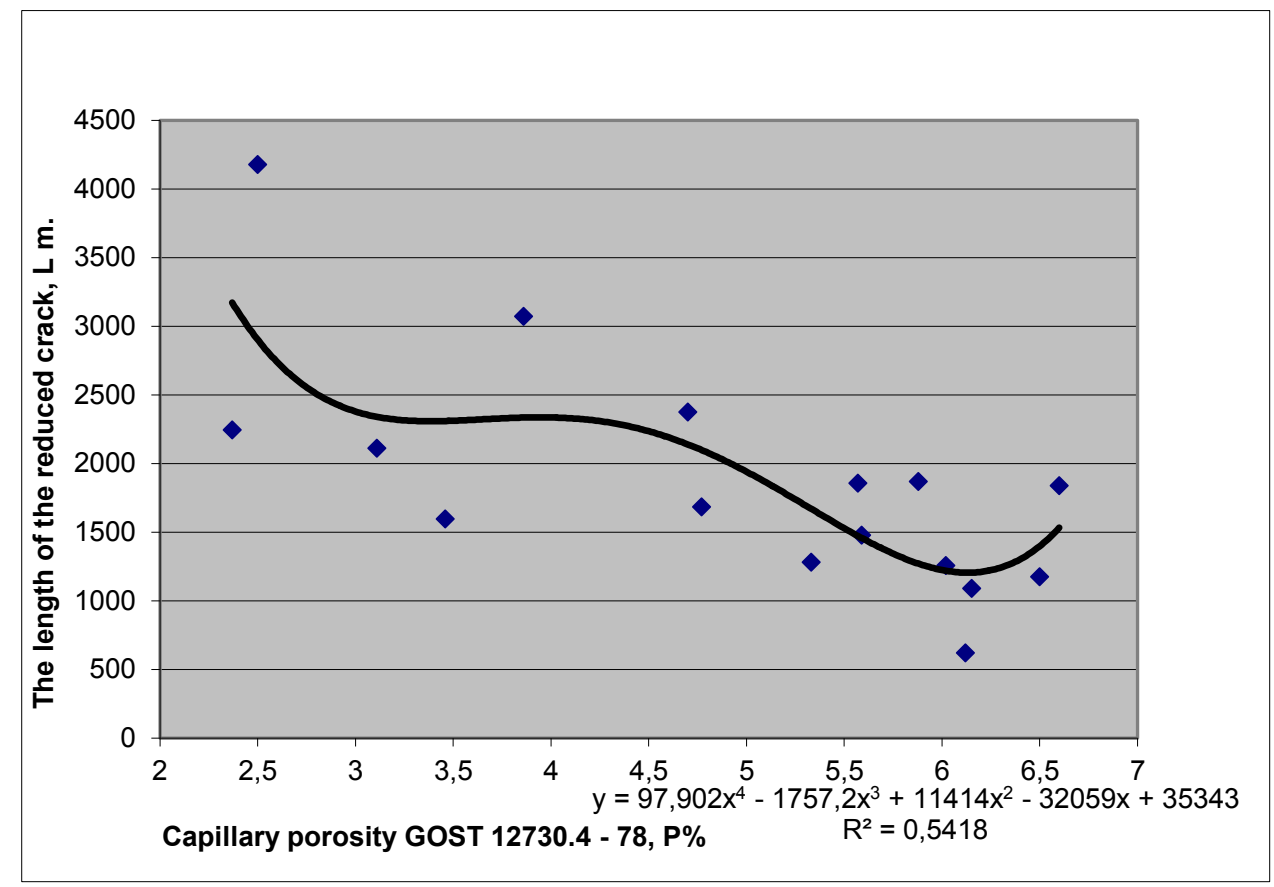

Fig. 1. Graphics of the dependence of the length of the reduced crack, in air-dry samples on the capillary porosity of concrete.

The graphics shown in Figure 1 shows the dependence of the length of the reduced crack $\left(L_{r c}\right)$ on the porosity of the concrete $\left(P_{o}\right)$, described by the correlation equation of the form:

$$
L_{r c}=97,902 P_{0}^{4}-1757,2 P_{0}^{2}-32059 P_{0}+35343
$$

It is interesting to note that the reliability and correlation coefficients for air-dry samples are $R^{2}=0.5418$ and $R=0.73$.

It is also established that between the porosity of concrete $\left(P_{o}\right)$ and the length of the reduced crack for samples in the water-saturated state, there is a linear relationship shown in Figure 2.

The presented dependence is described by the correlation equation with reliability and correlation coefficients equal to $R^{2}=0,806$ и $R=0,90$ :

$$
L_{r c}=4017,8-510,54 P_{o}
$$

The absolute values of the length of the reduced crack are within a few hundred meters, which makes it possible to classify the criterion of crack resistance of concrete to a sufficiently sensitive characteristic of this material to the state and features of its structure. 


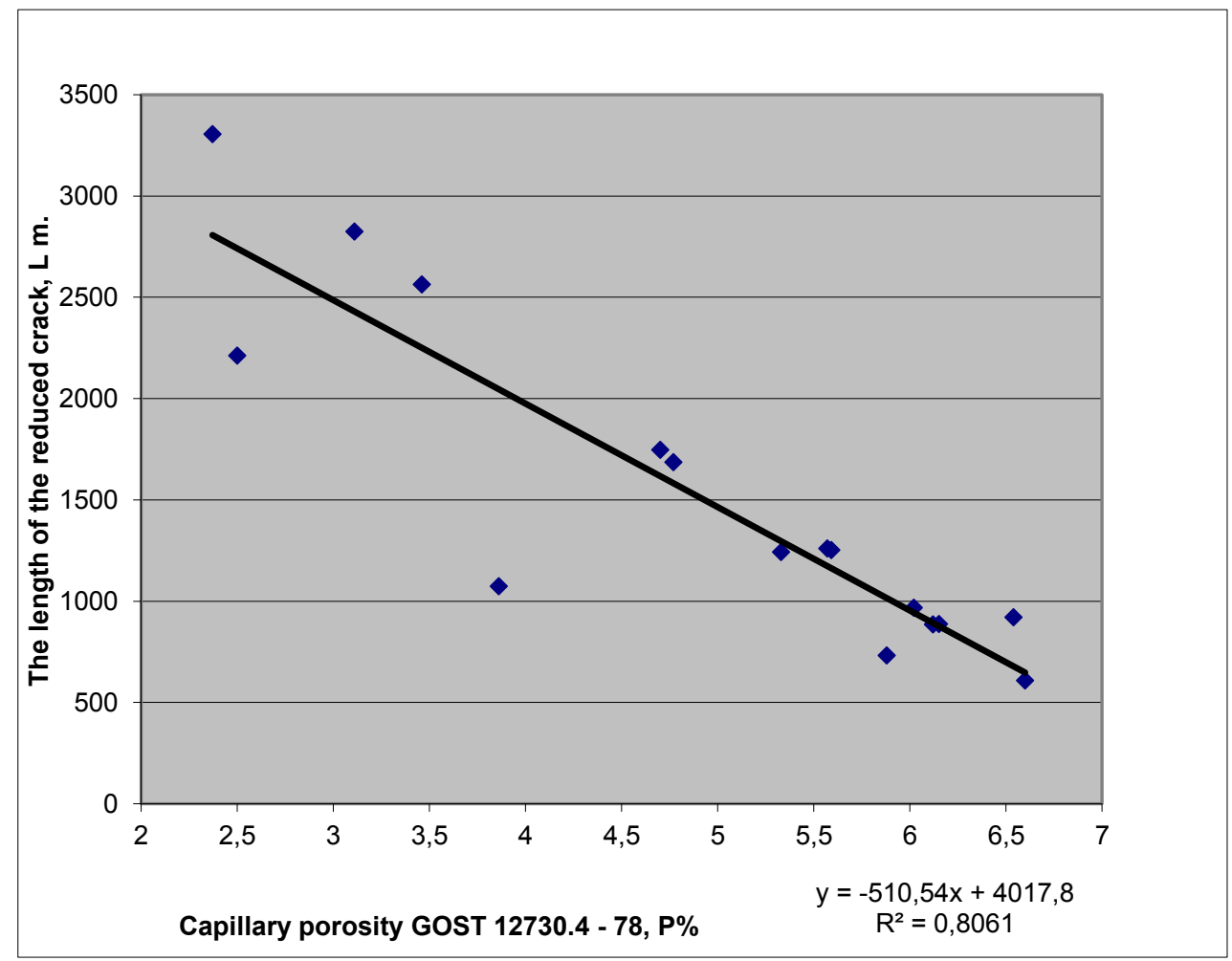

Fig. 2. Graphics of the dependence of the length of the reduced crack in water-saturated samples on the capillary porosity of concrete.

Practical implementation of the developed technique for determining the fracture hardness of concrete can be carried out using nondestructive acoustic methods and destroying mechanical methods. The values of the elasticity modulus and Poisson's ratio can be determined from the velocities of transmission of longitudinal and shear ultrasonic waves, according to widely known and approved methods [1-5]. When determining the compressive strength, a standard technique is used with the use of concrete cubes, which are destroyed by compression.

To determine the values of surface energy, a technique developed by the authors of this work is used as a sample a concrete plate torn apart by tensile forces. As shown by the results of experimental studies, the presented technique has sufficient reliability, sensitivity and can be used as a criterion for crack resistance of concrete.

\section{Conclusion}

The method proposed by the authors for determining the crack resistance of concrete is based on studies of the processes of its destruction by various types of external action. We analyze power, temperature, humidity and hydrostatic conditions of operation of samples. The obtained dependences confirm that the proposed indicator "length of the reduced crack" is distinguished by high sensitivity and reliability and can be used for qualitative and quantitative evaluation of the structure of concrete. 


\section{References}

1. M.D. Mosesov, Traditions and innovations in construction and architecture. Construction: a collection of thesis, 28-31 (2015)

2. M.D. Mosesov, Traditions and innovations in construction and architecture. Construction: a collection of thesis, 51-54 (2016)

3. M.D. Mosesov, Traditions and innovations in construction and architecture. Construction: a collection of thesis, 61-65 (2017)

4. V.A. Zubkov, N.V. Kondratieva, Patent for the invention RUS 226653323.03 .2004

5. V.A. Zubkov, I.V. Semerkov, E.V. Zubkov, Concrete and reinforced concrete, 7, 9 (1993)

6. V.Yu. Alpatov, Patent for utility model RUS 11117229.10 .2009

7. A. A. Lukin, V.Yu. Alpatov, Science News of Eastern Technical Universities 3, 38-42 (2016)

8. A. A. Lukin, V.Yu. Alpatov, and etc., Bulletin of SSUACE, 2 (23), 4-9 (2016)

9. A. A. Lukin, V.Yu. Alpatov, and etc., Construction. New technologies, new equipment 9, 52-55 (2016)

10. I.S. Kholopov, A.O. Lukin, et al., Building materials, equipment, technologies of the XXI century 12 (155), 40-45 (2011)

11. I.S. Kholopov, V.Yu. Alpatov, A.V. Soloviev, Science and Education in the 21st Century. Collection of proceedings on the materials of the International Scientific and Practical Conference: in 34 parts, 145-147 (2013)

12. I.S. Kholopov, V.Yu. Alpatov, et al., Collection of reports of the scientific and practical conference dedicated to the 100th anniversary of Professor E.I. Beleni "Calculation and design of metal structures", 236-241 (2013)

13. V.Yu. Alpatov, A. A. Sakharov, and etc., MATEC Web Conf. 86, 02021 (2016)

14. V.Yu. Alpatov, A. A. Lukin, Procedia Engineering 111, 20-29 (2015), ISSN 1877 7058

15. V.Yu. Alpatov, MATEC Web of Conferences 117, 00007 (2017)

16. V.Yu. Alpatov, S.M. Petrov, MATEC Web of Conferences 106, 04002 (2017)

17. V.Yu. Alpatov, O. Yu. Veremeenko, and etc., MATEC Web of Conferences 86, 02015 (2016)

18. V.Yu. Alpatov, MATEC Web of Conferences 86, 02005 (2016)

19. A. A. Lukin, and etc., Procedia Engineering 153, 414-418 (2016), ISSN 1877-7058

20. V.Yu. Alpatov, O.V. Alpatova, Scientific Review 24, 51-56 (2015)

21. V.Yu. Alpatov, Postgraduate Student of the Samara Province 2, 22-24 (2001)

22. I.L. Golenkov, V.Yu. Alpatov, Bulletin of post-graduate students of the Samara Region 1, 23-25 (2002)

23. I.S. Kholopov, V.Yu. Alpatov, Bulletin of higher educational establishments. Construction 10, 41-48 (2002)

24. V.Yu. Alpatov, I.S. Kholopov, Modern building constructions from metal and wood: a collection of scientific papers, 259-270 (2005)

25. V.Yu. Alpatov, Actual problems in construction and architecture. Education. The science. Practice, 474 (2007) 
26. V.Yu. Alpatov, Actual problems in construction and architecture. Education. The science. Practice, 190 (2009)

27. V.Yu. Alpatov, Building Bulletin of the Russian Engineering Academy: Works of the Section "Construction", 10, 195-201 (2009)

28. V.Yu. Alpatov, I.S. Kholopov, Metal Constructions 1, 47-58 (2009)

29. V.P. Popov, S.F. Korenkova, D.V. Popov, Izvestiya VUZov. Construction 10, 3-6 (2010)

30. V.P. Popov, A.Yu. Davidenko, Building Materials 3, 5-9 (2012)

31. V.P. Popov, A.Yu. Davidenko, D.V. Popov, Materials of the 1st International Scientific and Practical Conference "Science and Education", Engineering Sciences, 18-20 (2014)

32. A.A. Griffith, Phil. Trans. Roy. Soc. Series, A-221, 163-198 (1921)

33. S.N. Zhurkov, Bulletin of the Academy of Sciences of the USSR 11, 78-82 (1957)

34. V.P. Popov, A.Yu. Davidenko, Patent for the invention RUS No. 2390018 No. 2008149671/03, Bul. No. 14, 6

35. S.M. Ampilov, V.P. Popov, Patent for the invention RUS 2235322 No. 2002122529 , Bul. No. 24, 9 